\title{
ANÁLISE DA INFLUÊNCIA DE PORÕES VENTILADOS NO ESTADO DE CONSERVAÇÃO DE EDIFICAÇÕES HISTÓRICAS COM NOVOS USOS NA CIDADE DE PELOTAS/RS
}

\section{Influence analysis of ventilated basement in the condition of conservation of historical buildings with new uses in the city of Pelotas/RS}

\author{
Mariana Estima Silva ${ }^{1}$, Ariela da Silva Torres ${ }^{2}$, Isabel Tourinho Salamoni ${ }^{3}$
}

Recebido em 25 de março de 2017; aceito em 10 de agosto de 2017; disponível on-line em 07 de novembro de 2017.

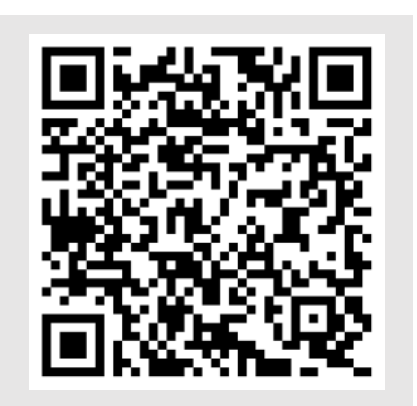

PALAVRAS CHAVE:

Preservação do patrimônio; Prédios Históricos; Retrofit; Manifestações Patológicas; Microclima.

\section{KEYWORDS:}

Preservation of heritage; Historical Buildings; Retrofit; Pathological Manifestations; Microclim.

\begin{abstract}
RESUMO: Atualmente, a alteração do uso original de prédios históricos por espaços expositivos é uma alternativa de preservação destas construções. Entretanto, é comum o surgimento de danos após o processo de retrofit, em razão das alterações microclimáticas ideais para o novo uso. A fim de conhecer as potencialidades do prédio em razão dos sistemas construtivos, o objetivo principal desta pesquisa é analisar a influência da existência de porões ventilados, em prédios históricos com novos usos, na incidência de manifestações patológicas. Para isso, foram analisadas três edificações do século XIX, das quais duas possuem porão ventilado. Para a análise foram escolhidos ambientes com mesma orientação solar e com o novo uso de sala de exposições. $O$ estudo contou com levantamentos visuais e fotográficos trimestrais, durante 12 meses, a fim de avaliar o comportamento dessas manifestações. Além disso, imagens termográficas das paredes internas foram realizadas, para visualizar o comportamento da umidade ascendente nesses espaços. Concluiu-se que, para prédios sem porão ventilado, não são indicados novos usos que impossibilitem as trocas de ar periódicas e a incidência de luz solar em seu interior, visto que tendem a causar danos aos materiais construtivos.
\end{abstract}

ABSTRACT: Currently, the alteration of the original use of historic buildings by exhibition rooms is an alternative of preservation of these constructions. However, it is common that the building develop damages after the retrofit process, due to the ideal microclimatic changes for the new use. In order to know the potentialities of the buildings that related to the constructive systems, the main objective of this paper is to analyze the influence of the existence of ventilated basements, in historical buildings with new uses, in the incidence of pathological manifestations. For this, three buildings of the nineteenth century were analyzed, two of this have ventilated basement. For the analysis were chosen environments with the same solar orientation and with the new use of the exhibition room. For the study had quarterly visual and photographic surveys for 12 months in order to evaluate the behavior of the pathological manifestations. In addition, thermographic images of the inner walls were performed, to visualize the behavior of ascent humidity in these spaces. It was concluded that, for buildings without a ventilated basement, no new uses are indicated that would prevent periodic air changes and the incidence of sunlight in their interior, since they tend to cause damage to the building materials.

\footnotetext{
${ }^{1}$ e-mail: estimasilva.m@gmail.com (M. E. Silva)

Arquiteta e Urbanista, Mestranda do Programa de Pós-Graduação em Arquitetura e Urbanismo, Universidade Federal de Pelotas.

2e-mail: arielatorres@gmail.com (A.S. Torres )

Doutora em Engenharia Civil, Professora Titular, Programa de Pós-Graduação em Arquitetura e Urbanismo, Universidade Federal de Pelotas.

3 e-mail: isalamoni@gmail.com ( I. T. Salamoni )

Doutora em Engenharia Civil, Professora Titular, Programa de Pós-Graduação em Arquitetura e Urbanismo, Universidade Federal de Pelotas. 


\section{INTRODUÇÃO}

O processo de retrofit, ou reabilitação, de prédios históricos é uma alternativa para a conservação dessas construções. Nesse processo a edificação é restaurada, tendo seu uso original substituído por um novo uso, pertinente a realidade da sociedade atual, tornando possível a economia de recursos naturais e a preservação o patrimônio histórico edificado (Jacobs, 2009).

O novo uso de museus, ou espaços expositivos, é cada dia mais frequente em prédios históricos. Entretanto, é constante o fato de edificações com este novo uso apresentarem manifestações patológicas em seus elementos construtivos, pouco tempo após passarem por retrofit. Isso pode acontecer pois, em muitos casos, a edificação não tem o potencial para abrigar espaços expositivos, dificultando 0 seu funcionamento adequado e provocando o surgimento de danos na construção. Dessa forma, torna-se imprescindível um estudo sobre o comportamento das edificações, a fim de prevenir danos e adequá-la ao uso de museus, ou, até mesmo, escolher outro novo uso (Silva e Henriques, 2014; Ribeiro e Lomardo, 2014; Guerra et al., 2016).

Pelotas, cidade do extremo sul do Brasil, possuiu, no século XIX, uma importante relação com a cidade francesa de Paris. Hoje o município apresenta um vasto exemplar de edificações de valor histórico, remanescentes desta época, a qual representou seu auge econômico (Secretaria da Cultura, 2008). Além disso, e para afirmar a relevância deste trabalho para a cidade, no ano de 2006 foi instituído o Sistema de Museus de Pelotas, fato que impulsionou o uso de prédios históricos por espaços de exposição (Pelotas, 2006).

Além disso, a cidade apresenta verões quentes $\mathrm{e}$ invernos com temperaturas mais amenas, porém com bastante precipitação, caracterizando um clima subtropical úmido. A média anual de temperatura é de 17,8 으, enquanto a umidade relativa do ar apresenta-se, em média, $80,7 \%$ ao ano. Esses dados são de grande importância para o trabalho, visto que altas taxas de umidade relativa do ar influenciam o surgimento de manifestações patológicas relacionadas a estes parâmetros no interior das edificações (Empresa Brasileira de Pesquisa Agropecuária, 2016).

\section{OBJETIVO}

Conhecendo as necessidades dos espaços destinados a salas de exposições e, sabendo os danos que uma alteração no microclima pode gerar em edificações históricas reabilitadas para esse novo uso, este trabalho tem como objetivo analisar a influência da existência de porões ventilados no surgimento de manifestações patológicas relacionadas a umidade. Este trabalho é um estudo de caso dos Casarões 2, 6 e 8 do século XIX, na cidade de Pelotas, no Brasil, que passaram por processo de retrofit e hoje abrigam salas de exposições.

\section{REVISÃO BIBLIOGRÁFICA}

\subsection{O NOVO USO DE ESPAÇOS EXPOSITIVOS EM PRÉDIOS HISTÓRICOS}

A adaptação de prédios históricos por novos usos foi impulsionada na segunda metade do século XX, na Europa. A partir da preocupação com a preservação do patrimônio edificado, surgiu a necessidade de torná-lo útil para a sociedade. Foi então que, a partir da publicação da Carta de Atenas em 1933, os prédios públicos pertencentes ao patrimônio histórico, passaram a abrigar, principalmente, o uso de museus e espaços para exposições (Rodrigues, 2012).

Entretanto, apesar de contribuir com a conservação dos prédios históricos, o novo uso de espaços expositivos é uma problemática nos projetos de retrofit. Segundo Barranha (2012), os programas de espaços destinados a exposições estão cada vez mais exigentes, nos aspectos de controle de temperatura, umidade relativa do ar, poluição atmosférica e iluminação, entre outros. Dessa forma, prédios históricos que recebem estes espaços, muitas vezes não suprem as necessidades do seu novo uso, sendo necessária a instalação de 
climatizadores artificiais, ou, até mesmo, a construção de novos prédios anexos.

Atualmente, no Brasil, a maior parte dos museus está localizada em prédios já existentes. Dentre estes prédios, grande parte é tombada, tornando difícil a instalação de equipamentos para a climatização controlada dos ambientes internos. Sendo, mais difícil ainda, a alteração de elementos construtivos para condicionamento passivo do microclima destes espaços (Ribeiro e Lomardo, 2014).

\subsection{MICROCLIMA HISTÓRICO VERSUS MICROCLIMA MUSEOLÓGICO}

Mendes (2013), afirma que, para abrigar o novo uso de espaços expositivos, é preciso conhecer o comportamento microclimático da edificação. Assim, é possível tirar proveito de suas características, para as diferentes necessidades do programa museológico a ser implantado no processo de retrofit.

Diversos são os estudos que estipulam índices ideais para a conservação de acervos expositivos, principalmente para os parâmetros ambientais de temperatura, umidade relativa do ar e iluminação. Michalski (2016), realizou um levantamento destes trabalhos ao longo dos anos, chegando aos principais utilizados na atualidade. Existem valores considerados ideais para a maior parte dos materiais expostos e climas onde estão instalados os museus, é o caso das publicações do International Institute for Conservation Historic and Artistic Works - IIC. Outros trabalhos, porém, consideram questões mais específicas de conservação, que dependerão diretamente do material que está sendo exposto e do nível de controle que se deseja obter. Este é o caso da American Society of Heating, Refrigerating and AirConditioning Engineers - ASHRAE, que em seus manuais possui um capítulo sobre questões de controle ambiental para ambientes de museus, galerias, arquivos e livrarias (Michalski, 2016).

Estudos realizados por Silva e Henriques (2014; 2015) concluíram que em edificações antigas, os materiais construtivos podem sofrer danos irreversíveis quando seu microclima é modificado. Isso acontece em diversos processos de retrofit, que implementam climatização artificial, ou modificam o modo de operação dos espaços de forma abrupta, a fim de conservar acervos ou até mesmo proporcionar melhores condições de conforto ambiental para os usuários, alterando o microclima histórico. Os materiais construtivos costumam aclimatar-se às condições ambientais quando expostos por longos períodos, quando estas condições se alteram, existe o surgimento de manifestações patológicas.

Sendo assim, a preocupação com a conservação do acervo expositivo deve estar acompanhada da necessidade de conservação dos materiais construtivos do prédio. Portanto, além de conhecer o microclima para estudar a potencialidade da construção para o uso de espaços expositivos, é preciso também não modificá-lo em excesso, a fim de não provocar danos em seus elementos construtivos.

\subsection{MANIFESTAÇÕES PATOLÓGICAS POR UMIDADE EM PRÉDIOS HISTÓRICOS}

A umidade relativa do ar é um parâmetro ambiental acelerador de processos de biodeterioração nos materiais. Sua presença em excesso aliada a variações diárias pode provocar o surgimento de diversas manifestações patológicas (Sterflinger, 2010; Mendes, 2013).

A temperatura do ar influencia diretamente as taxas de umidade relativa, sendo um parâmetro importante para a conservação dos materiais construtivos. A iluminação, fundamental para permitir a visualização das exposições, pode tanto deteriorar materiais por meio de sua fração ultravioleta, quanto influenciar a temperatura do ar, por sua fração geradora de calor (Bencatel, 2012; Mendes, 2013).

Guerra et al. (2016), afirmam que a modificação no modo de operação dos usuários, em função de um novo uso, muitas vezes contribui para o surgimento de danos. Em ambientes usados por exposições é necessária uma menor incidência de luz para proteger o acervo e, também, para construir "cenários" de luz e sombra. Dessa forma, 
janelas são fechadas, impedindo a penetração de luz natural, o que modifica os valores de temperatura e impede, muitas vezes, a ventilação (Guerra, 2012; Guerra et al., 2016).

Em ambientes com pouca ventilação, acontece um maior acúmulo de sujidades sobre os materiais construtivos. Associado a taxas de umidade relativa do ar mais altas, em função da falta de trocas de ar, e pouca incidência de radiação solar, provoca uma manifestação patológica bastante comum, os fungos filamentosos (Sterflinger, 2010; Guerra et al., 2016).

O uso original de edificações do século XIX, objeto deste estudo, previa, em grande parte das vezes, as necessidades básicas de ventilação e iluminação natural. Isso acontecia por meio de paredes espessas, pés-direitos altos, grande número de janelas e com grandes dimensões, além de porões altos com gateiras. Esse último sistema, era usado para ventilar o piso do pavimento térreo, dessa forma, a umidade do solo poderia até mesmo ascender pela parede, mas não alcançaria o interior do ambiente (Secretaria Municipal da Cultura, 2008).

\section{METODOLOGIA}

A metodologia deste trabalho foi dividida em três etapas, e estão descritas nos itens a seguir.

\subsection{CARACTERIZAÇÃO DO OBJETO DE ESTUDO}

Para este estudo foram escolhidas três edificações do século XIX, na cidade de Pelotas, tombadas a nível nacional, enquanto conjunto (Instituto do Patrimônio Histórico e Artístico Nacional, 2014).

O Casarão 2 (Figura 1), a mais antiga dentre as três construções, foi edificada no ano de 1830, entretanto foi reformada em 1880, ano em que recebeu características do estilo eclético. Por ter sido construída anteriormente, esse é o único prédio do conjunto que não possui porão alto para ventilação dos assoalhos de madeira do pavimento térreo. Em 2004, o prédio passou por retrofit, recebendo o Centro Cultural Adail Bento Costa. O Casarão 6 (Figura 2), localizado entre as demais, foi construído em 1879. No ano de 2010 o prédio foi entregue a sociedade como Museu da Cidade de Pelotas, após longo processo de retrofit. A outra edificação do conjunto é o Casarão 8 (Figura 3), construído em 1878. Este prédio ficou muito tempo em estado de abandono, até que, em 2011, teve início seu processo de retrofit. Hoje o Casarão 8 abriga o Museu do Doce (Secretaria Municipal da Cultura, 2008; Guerra, 2012; Instituto do Patrimônio Histórico e Artístico Nacional, 2014).

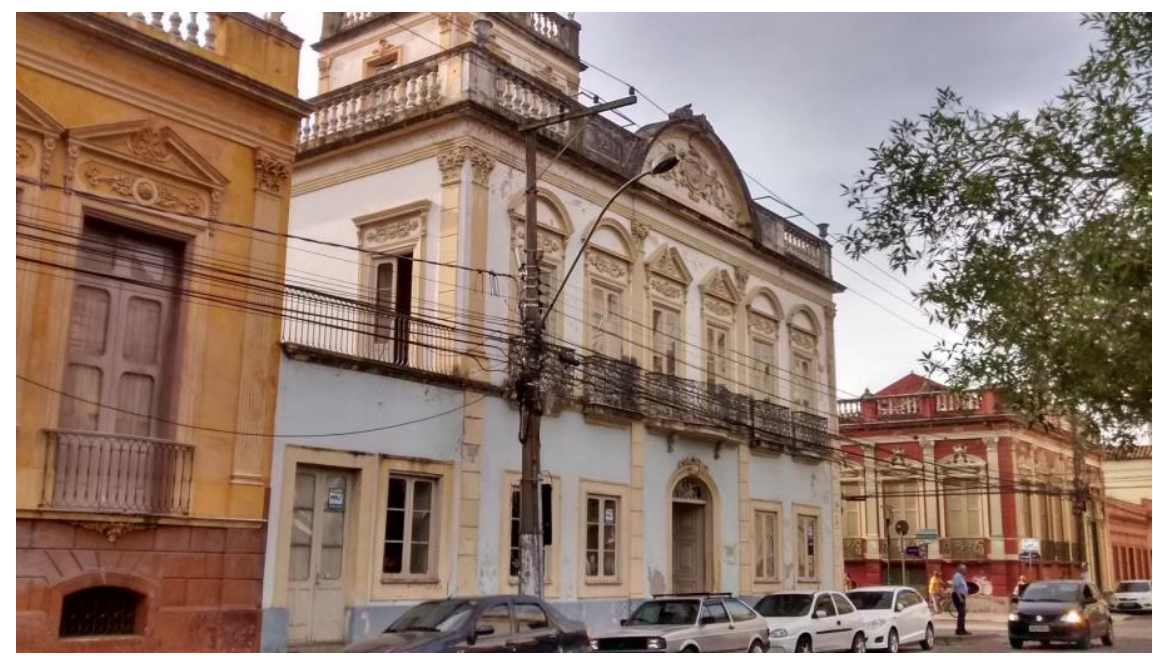

FIGURA 1: Fachada principal do Casarão 2.

FONTE: as autoras. 


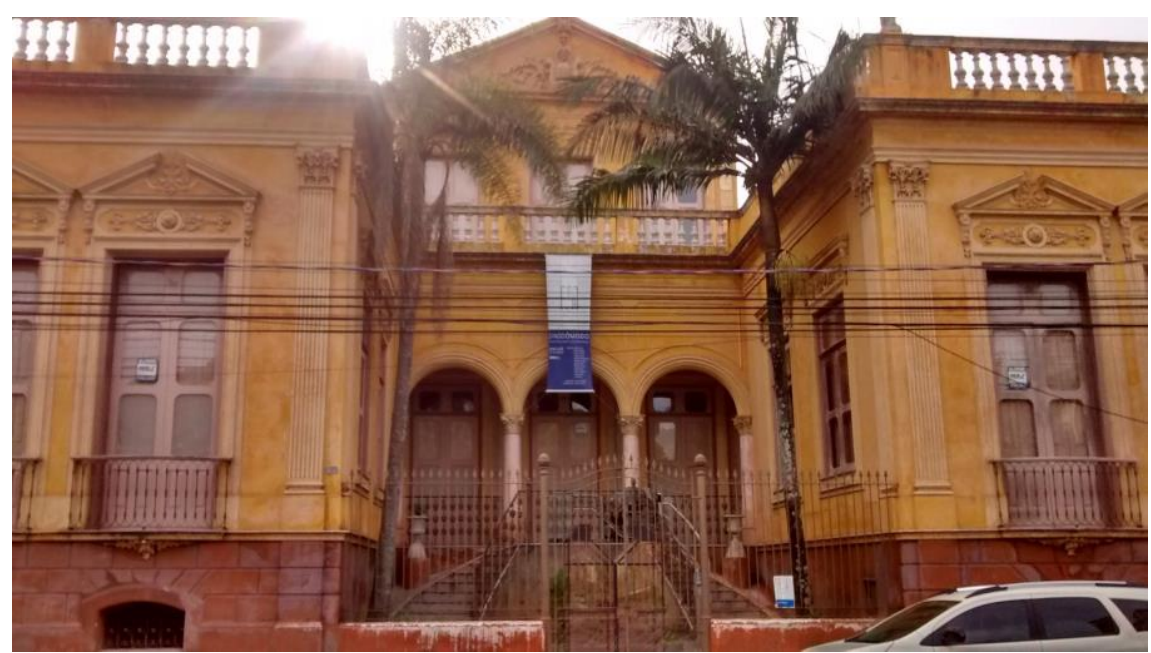

FIGURA 2: Fachada principal do Casarão 6.

FONTE: as autoras.

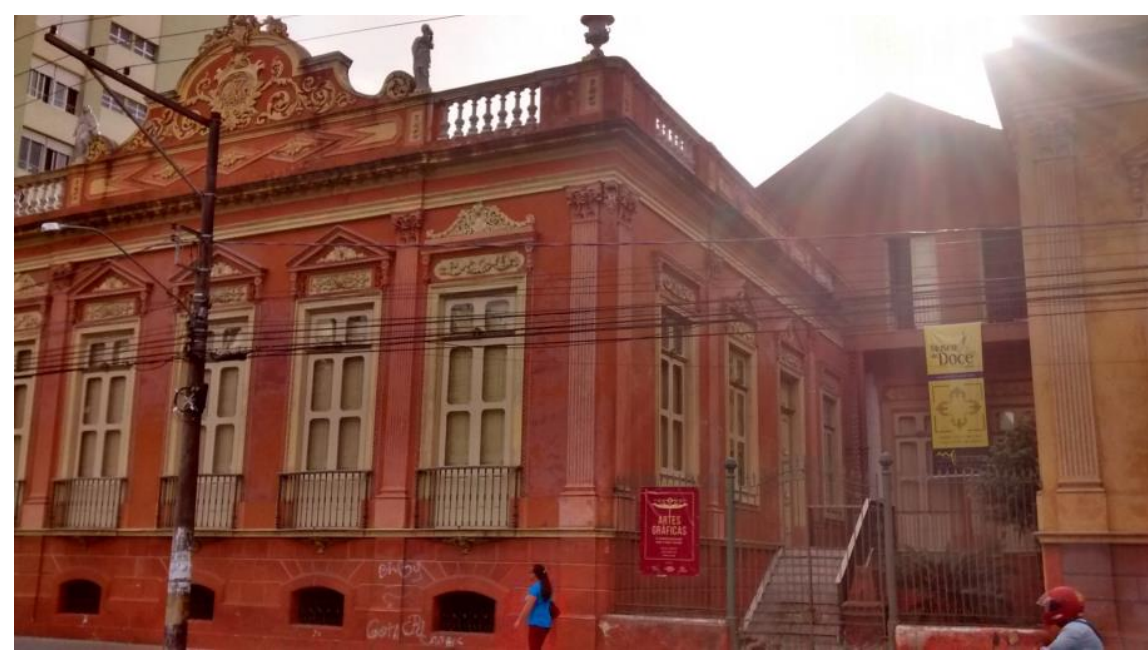

FIGURA 3: Fachada principal do Casarão 8.

FONTE: as autoras.

Foram escolhidos um ambiente em cada prédio, que tivessem o mesmo uso, o de sala de exposições. Além disso, os três ambientes têm orientações norte e oeste, com janelas nessas fachadas. Outro aspecto foi a área de vidro dos ambientes escolhidos, que são similares entre eles. No Casarão 2, o ambiente possui $6,44 \mathrm{~m}^{2}$ de áreas de vidro, no Casarão 6 essa área é de 6,91 m², enquanto no Casarão 8 a área de vidro é de 7,32 $\mathrm{m}^{2}$. Isso permite comparar os três ambientes com o menor número de variáveis possíveis, além do fato de existir o porão alto.

As três edificações possuem sistema construtivo similar, com paredes portantes em alvenaria de tijolo de barro rebocadas. Dessa forma, suas paredes, principalmente as externas, são bastante espessas, algumas chegando a 0,90 metros de espessura. Internamente, o estuque é utilizado como elemento de vedação entre alguns ambientes. As janelas e portas são de madeira e vidro. No Casarão 2, o ambiente possui piso de tacos de madeira emoldurados por ladrilhos hidráulicos e forro de madeira. No Casarão 6, o piso do ambiente é de assoalho de madeira e o forro em estuque. 0 ambiente do Casarão 8 possui piso em assoalho de madeira e forro em estuque ornamentado.

$$
\text { Apesar de usos, sistemas }
$$
construtivos, orientações solares, áreas de vidro e acabamentos similares, existe a presença de porão ventilado por gateiras apenas nos Casarões 6 e 8 . Isso permitirá visualizar a influência deste elemento no surgimento de manifestações patológicas ligadas à umidade quando estas edificações são ocupadas por um mesmo uso. 


\subsection{LEVANTAMENTOS DAS MANIFESTAÇÕES PATOLÓGICAS}

Através de um acompanhamento trimestral, durante um período de 12 meses, realizou-se o levantamento das manifestações patológicas existentes nos ambientes. Estes levantamentos foram realizados a cada troca de estação, a fim de relacionar o surgimento, crescimento ou desaparecimento das anomalias com as condições climáticas do entorno.

Para coleta de dados foram realizados levantamentos fotográficos das manifestações encontradas. Foram elaboradas Fichas de Identificação para cada anomalia encontrada, contendo suas imagens, características e diagnóstico, com possíveis origens e causas (Lichtenstein, 1986).

O primeiro levantamento foi realizado no dia 21 de dezembro de 2015, início do período de verão. Para o período de outono, outro levantamento foi realizado no dia 22 de março de 2016. Marcando o início do período de inverno realizou-se o levantamento no dia 4 de junho de 2016. E, para a primavera, o levantamento foi realizado no dia 13 de setembro de 2016. O último levantamento do estado de conservação dos ambientes foi realizado no dia 20 de dezembro de 2016.

Todos os ambientes foram vistoriados no mesmo dia de levantamento, com mesmas condições climáticas externas, a fim de diminuir a possibilidade de variação de intensidade das anomalias entre dias diferentes.

\subsection{LEVANTAMENTO POR TERMOGRAFIA}

A fim de diagnosticar as manifestações patológicas, segundo Lichtenstein (1986), é possível realizar ensaios auxiliares. Sendo assim, optou-se por realizar o levantamento dos ambientes com o uso da termografia, juntamente com o levantamento final, no dia 20 de dezembro de 2016.

A termografia permite a visualização da presença de umidade no interior dos elementos construtivos, por meio de imagens térmicas que representam a temperatura superficial dos materiais. Assim, a umidade que não conseguimos perceber, torna-se visível através dessas imagens, facilitando o diagnóstico sem comprometer a estrutura do prédio (Silva, 2012).

O fato de manifestações patológicas poderem estar relacionadas a diferentes formas de presença de umidade: ascendente por capilaridade, acidental, por condensação e por infiltração levou à necessidade de recorrer a um ensaio que permitisse esta diferenciação (Lourenço et al., 2006). Escolheu-se, então, este ensaio para caracterizar o comportamento dos elementos construtivos em relação à presença de umidade, visto que, no decorrer dos levantamentos esta informação se tornou de extrema importância.

\section{RESULTADOS E DISCUSSÕES}

Para visualização dos resultados optou-se por dividi-los por levantamento.

\subsection{RESULTADOS DO LEVANTAMENTO INICIAL, DEZEMBRO DE 2015}

Dentre os três ambientes levantados, no Casarão 2 foi onde encontrou-se maior quantidade de manifestações patológicas relacionadas a umidade. Para este prédio, foram elaboradas doze Fichas de Identificação. No Casarão 6, apenas três Fichas foram elaboradas, enquanto no Casarão 8, não foram encontradas manifestações patológicas relacionadas à umidade.

Foi possível visualizar, também, que além da maior quantidade, os danos causados aos materiais construtivos estavam mais intensificados no Casarão 2, enquanto no Casarão 6 as manifestações patológicas encontradas eram apenas superficiais.

As manifestações patológicas levantadas no Casarão 2 apresentavam-se, principalmente, nas paredes de alvenaria e numa altura inferior a 1 metro do piso. Encontrou-se, principalmente, descolamento com empolamento, eflorescências e bolor (Figuras 4). O bolor estava presente tanto superficialmente em elementos de madeira, principalmente nos postigos das janelas, quanto no reboco, dentro dos vazios provocados pelo descolamento. 


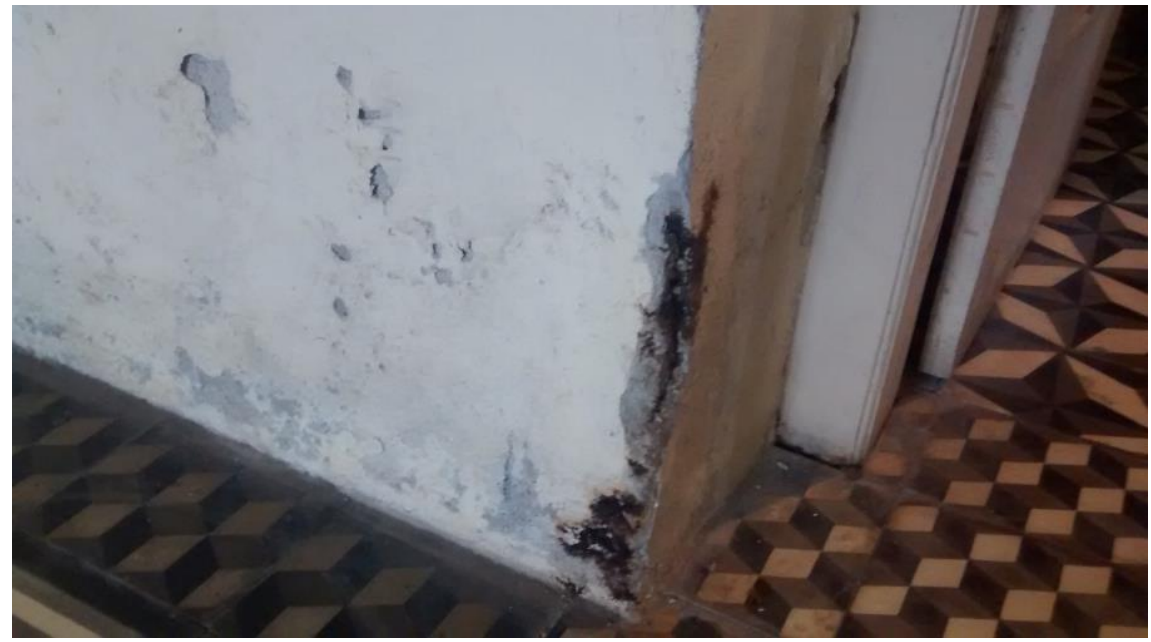

FIGURA 4: Descolamento e bolor em parede interna.

FONTE: as autoras.

Percebe-se que os danos nas paredes podem estar relacionados à umidade ascendente, visto que não atingem alturas significativas. Além disso, o ambiente não possui ventilação e insolação frequente, pela necessidade de gerar cenários de iluminação artificial às exposições, aumentando a umidade relativa do ar em seu interior. Sem trocas de ar, a umidade, que sobe por capilaridade, não é retirada do interior do espaço, provocando manifestações patológicas relacionadas à umidade por condensação, que é o caso dos fungos.

No Casarão 6, as manifestações
patológicas encontradas foram manchas
superficiais de bolor em elementos de madeira, principalmente nos postigos. $O$ fato de $\mathrm{o}$ ambiente não estar sendo utilizado no momento dos levantamentos, e encontrar-se fechado durante longos períodos, favorece o surgimento dessas anomalias.

\subsection{RESULTADOS DO LEVANTAMENTO DE MARÇO DE 2016}

No mês de março, após terminar o período de verão, as manifestações patológicas não apresentaram modificações significativas, nem mesmo aumento em quantidade no ambiente do Casarão 2 (Figuras 5 e 6). Foi possível visualizar as mesmas anomalias das fichas de identificação do levantamento anterior.

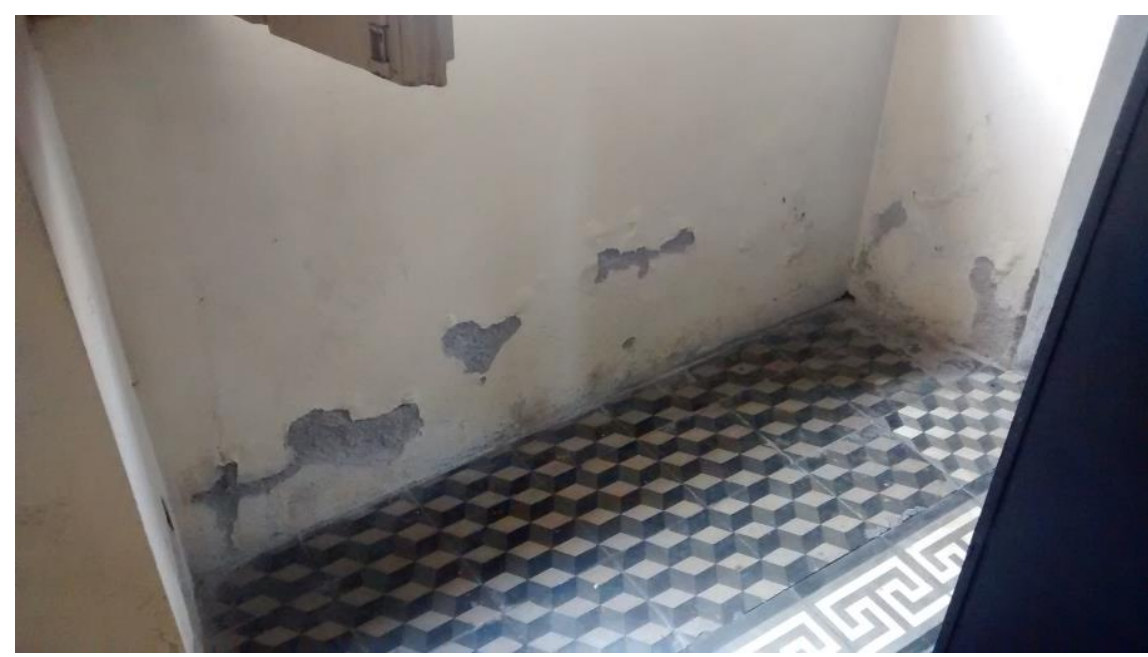

FIGURA 5: Descolamento com empolamento, levantamento de dezembro/2015. FONTE: as autoras. 


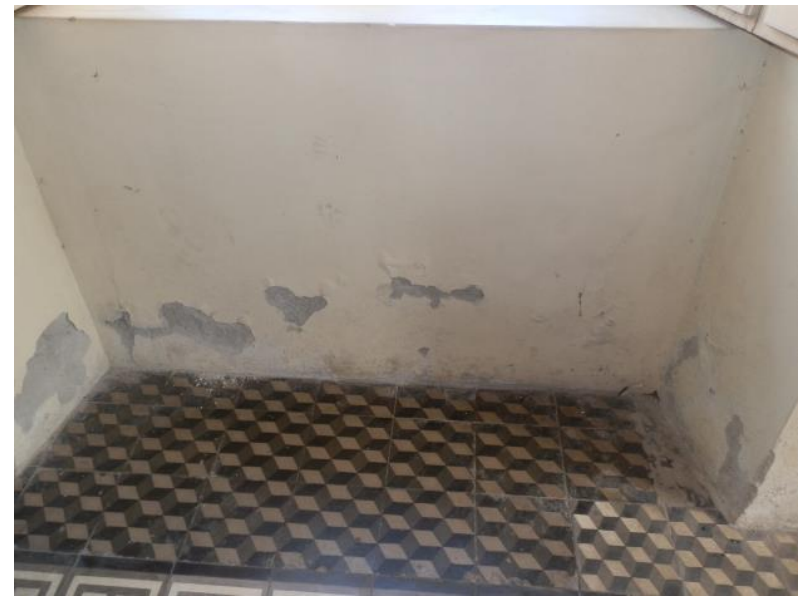

FIGURA 6: Descolamento com empolamento, levantamento de março/2016.

FONTE: as autoras.

Já no Casarão 6, foi possível perceber um aumento do número de manifestações patológicas. Contudo, os danos encontrados limitaram-se à superficialidade, ou seja, foi encontrado um maior número de manchas de bolor em elementos de madeira que podiam ser facilmente retirados com limpeza.

No Casarão 8, não foram encontradas manifestações patológicas relacionadas à presença de umidade.

\subsection{RESULTADOS DO LEVANTAMENTO DE JUNHO DE 2016}

No levantamento de junho, as anomalias também não sofreram alteração significativa no Casarão 2. No Casarão 6, foi possível perceber que os danos identificados no levantamento anterior permaneceram, entretanto, não sofreram aumento. 0 Casarão 8 permaneceu não apresentando manifestações patológicas relacionadas à umidade.

\subsection{RESULTADOS DO LEVANTAMENTO DE SETEMBRO DE 2016}

No mês de setembro, após todo o período de inverno, o agravamento das manifestações patológicas no Casarão 2 foi bastante significativo. Os danos já existentes, principalmente relacionados ao descolamento com empolamento, apresentaram aumento em sua área superficial. Nesta etapa, foram encontradas novas manifestações patológicas nos elementos de madeira das janelas, com apodrecimento dos mesmos, que podem ser associados à presença de umidade.

No Casarão 6, as manchas de bolor apresentaram aumento de intensidade (Figuras $7 \mathrm{e}$ 8). Além disso, pode-se perceber a presença do bolor também no forro de estuque ornamentado, e não somente nos elementos de madeira.

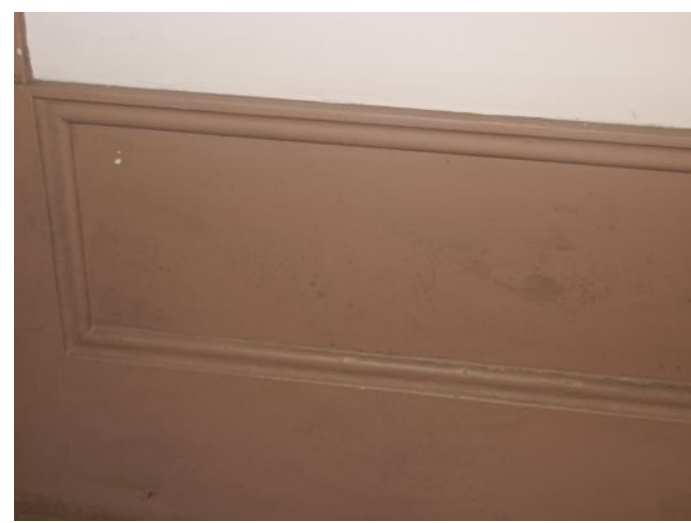

FIGURA 7: Pouca incidência de manchas de bolor, levantamento de junho/2016.

FONTE: as autoras. 


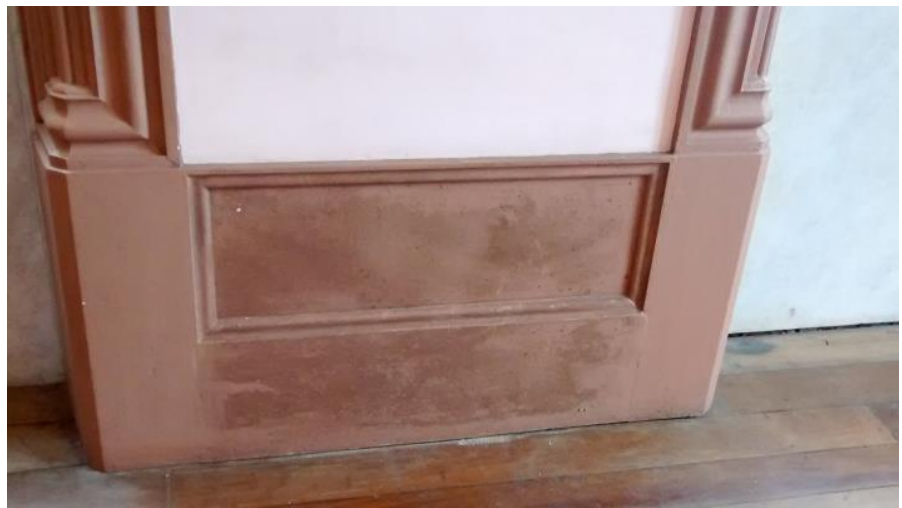

FIGURA 8: Aumento da intensidade das manchas de bolor, levantamento de setembro/2016.

FONTE: as autoras.

É possível dizer que, nos dois Casarões que já apresentavam manifestações patológicas, o inverno foi um importante acelerador deste processo. Pelo fato de os dois ambientes apresentarem ventilação e insolação irregular, os altos níveis de umidade relativa do ar da estação de inverno agravaram os danos já existentes. No Casarão 8, onde não haviam manifestações patológicas relacionadas à presença de umidade, 0 inverno não mostrou-se significativo, visto que não foram encontradas anomalias também neste levantamento.

\subsection{RESULTADOS DO LEVANTAMENTO FINAL, DEZEMBRO DE 2016}

Em relação ao primeiro levantamento, realizado 12 meses antes, foi possível perceber diferenças significativas na presença de manifestações patológicas, tanto no Casarão 2, quanto no Casarão 6. O Casarão 8 permaneceu todo o período sem apresentar danos relacionados à umidade.

Entretanto, em relação ao levantamento anterior, do mês de setembro, não percebeu-se nenhuma alteração significativa. As manifestações patológicas encontradas permaneceram, sem nenhum aumento. No Casarão 6 , as manchas de bolor não aumentaram, assim como não diminuíram.

\subsection{RESULTADOS DO LEVANTAMENTO COM TERMOGRAFIA}

Para o levantamento com termografia, foram realizadas fotografias de todas as paredes internas dos ambientes, a fim de perceber a presença da umidade ascendente, para confrontar com a presença de manifestações patológicas, bem como, com a existência dos porões ventilados.

Percebeu-se que, no Casarão 2, existe uma forte presença de umidade na base das paredes. Essa presença, está relacionada à umidade ascendente do solo, visto que a temperatura superficial das paredes, neste ponto, mostrou-se inferior às demais áreas, conforme Figura 9.
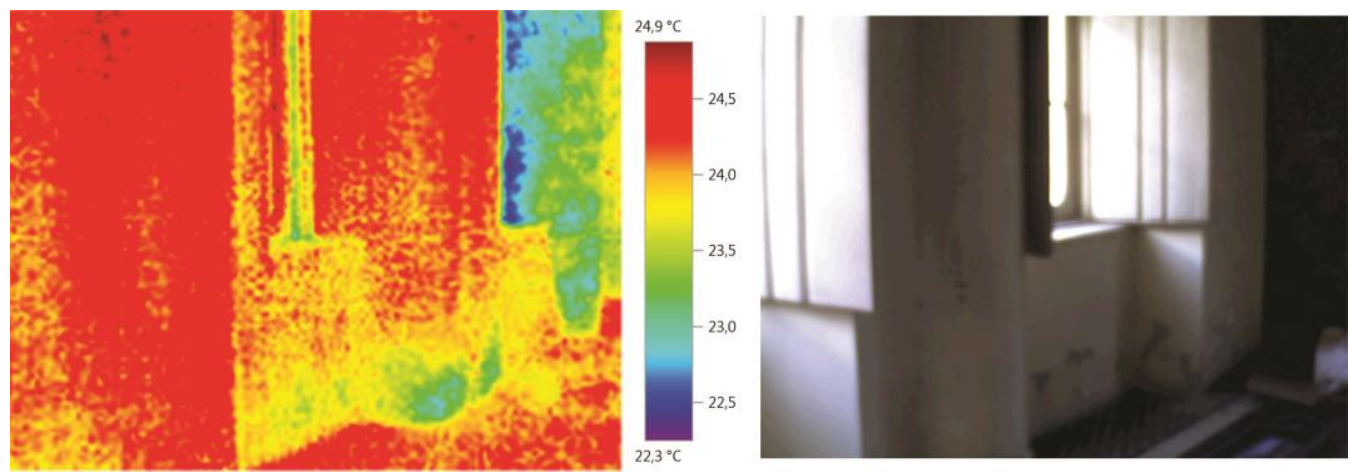

FIGURA 9: Imagem termográfica do ambiente no Casarão 2.

FONTE: as autoras. 
No Casarão 6, as temperaturas superficiais mostraram-se mais amenas em todos os elementos de madeira. Estes elementos estão presentes no piso, base das paredes e esquadrias. As paredes, apresentaram temperaturas mais elevadas que estes elementos, entretanto, não muito distantes, mostrando maior equilíbrio térmico em toda a superfície (Figura 10).

O Casarão 8, por sua vez, apresentou temperaturas superficiais das paredes bastante elevadas e distantes da temperatura superficial dos elementos de madeira (Figura 11). Estes elementos, assim como no Casarão 6, estão presentes no piso, na base das paredes e nas esquadrias. Entretanto, mesmo diferentes, é possível visualizar que a temperatura dos elementos de madeira é constante, ou seja, não existe presença de umidade próxima ao piso, e sim a temperatura superficial do próprio material que é menor.

Com o levantamento termográfico foi possível perceber que o Casarão 2 apresentou fontes de umidade ascendente do solo em suas paredes, diferentemente dos demais Casarões, que, devido à presença de porões ventilados, não apresentaram essa fonte de umidade.

\section{CONCLUSÕES}

Foi possível concluir que o Casarão 2, prédio que não possui porão ventilado, foi o que apresentou maior incidência de manifestações patológicas relacionadas à presença de umidade. Com a termografia, como ensaio auxiliar, foi possível visualizar estes pontos de umidade em locais onde as paredes apresentavam o maior número de danos.

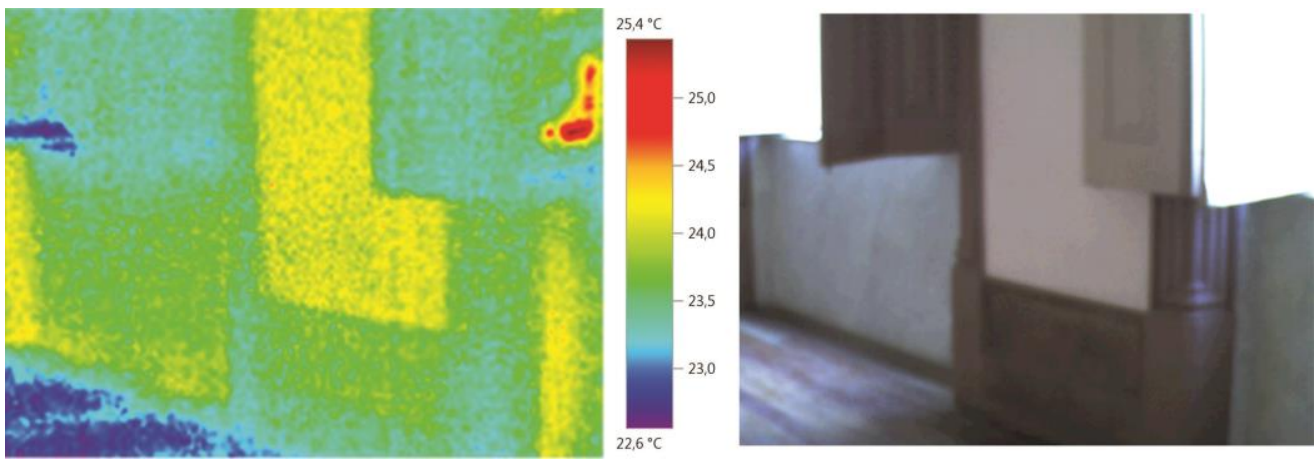

FIGURA 10: Imagem termográfica do ambiente no Casarão 6. FONTE: as autoras.
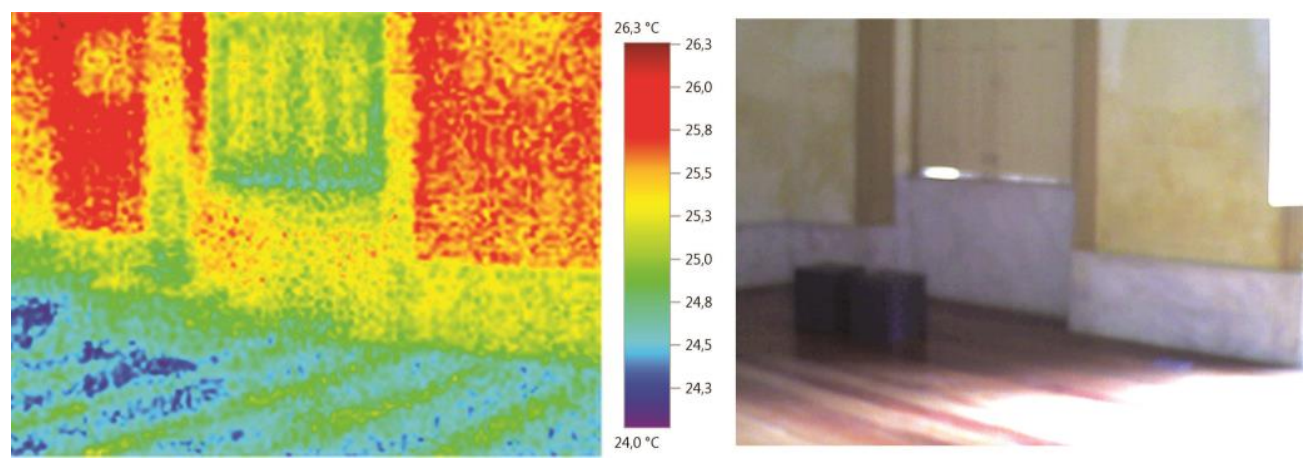

FIGURA 11: Imagem termográfica do ambiente no Casarão 8.

FONTE: as autoras. 
Além da incidência de manifestações patológicas por umidade ascendente, o uso dado à construção, o de espaços expositivos, não permite uma ventilação e insolação adequada, favorecendo também o surgimento de manifestações patológicas relacionadas à umidade por condensação.

Enquanto no Casarão 8, prédio com porão alto ventilado, não foram encontradas manifestações patológicas, no Casão 6, prédio com mesmas características, foi possível perceber a incidência de danos relacionados à umidade por condensação. Isso ocorreu pelo fato de o Casarão 6 não estar sendo utilizado, ou seja, sem condições favoráveis de ventilação e insolação, e não em função de seu sistema construtivo.

Dessa forma, pode-se dizer que, novos usos que não possibilitem proporcionar boas condições de ventilação e insolação, não devem ser destinados a prédios sem porão ventilado, visto que favorecem o surgimento e agravamento de danos, não contribuindo para sua conservação. Contudo, em prédios com porão alto, mesmo um uso que não possibilite tantas trocas de ar e incidência solar, sua conservação é mantida, já que permite a visualização de danos superficiais que podem ser finalizados apenas com limpezas periódicas.

\section{REFERÊNCIAS BIBLIOGRÁFICAS}

BARRANHA, H. Os museus como requalificação do património. 2012. Online. Disponível em: <http://www.patrimonio.pt/index.php/por-dentro/390os-museus-como-requalificacao-do-patrimonio $>$ Acesso em: 21 outubro 2015.

BENCATEL, D. O. Avaliação e redução do risco de dano associado à luz solar em duas novas galerias do Victoria and Albert Museum. Ensaios e práticas em museologia, Porto, v. 2, pp. 92-110, 2012.

EMPRESA BRASILEIRA DE PESQUISA AGROPECUÁRIA. Normais climatológicas, 1971-2000. Disponível em: <http://agromet.cpact.embrapa.br/estacao/normais.ht ml>. Acesso: 10 dez. 2016.
GUERRA, F.L. Biodeterioração de conjunto histórico do século XIX em Pelotas/RS: fungos filamentosos. 2012. 170 f. Dissertação (Mestrado em Arquitetura e Urbanismo) - Universidade Federal de Pelotas, Pelotas, Rio Grande do Sul, 2012.

GUERRA F. L.; PERES, R. M.; CUNHA, E. G.; GALLI, F. Analysis of the microclimate in historical building to assess the probability of recurrence of filamentous fungi. Recent Developments in Building Diagnosis Techniques, Porto: Faculdade de Engenharia, Universidade do Porto, pp. 195-213, 2016.

INSTITUTO DO PATRIMÔNIO HISTÓRICO E ARTÍSTICO NACIONAL. Pelotas. 2014. Disponível em: <http://portal.iphan.gov.br/pagina/detalhes/281>. Acesso: 20 fev. 2017.

JACOBS, J. Morte e vida de grandes cidades. São Paulo: WMFMartins Fontes, 2009.

LICHTENSTEIN, N.B. Patologia das Construções Procedimentos para Diagnóstico e Recuperação. Boletim Técnico. São Paulo: Departamento de Engenharia de Construção Civil da EPUSP, 35 p. 1986.

LOURENÇO, P. B.; LUSO, E.; ALMEIDA, M.G. Defects and moisture problems in buildings from historical city centres: a case study in Portugal. Building and environment, Portugal, v. 41, pp. 223-234, jan. 2006.

MENDES, I. M. M. Boas práticas a desenvolver em fase de projecto de arquitectura para adaptação de edifícios existentes a museus. 2013. 88 f. Dissertação (Mestrado em Museologia e Museografia) Universidade de Lisboa, Lisboa, 2013.

MICHALSKI, S. Climate guidelines for heritage collections: were we are in $\mathbf{2 0 1 4}$ and how we got here. Proceedings of the Smithsonian Institution Summit on the Museum Preservation Environment. Washington DC: Smithsonian Institution Scholarly Press, pp. 7-34, 2016.

PELOTAS. Decreto № 4.895, de 15 de setembro de 2006. Institui o Sistema de Museus do Município de Pelotas e dá outras providências. Disponível em: < http://www.pelotas.com.br/smm/smm/legislacao.pdf>. Acesso em: 20 fev. 2017. 
RIBEIRO, M. B.; LOMARDO, L. L. B. Parâmetros ambientais de conservação dos acervos museológicos aplicados na arquitetura de museus. In: PROCESSOS DE MUSEALIZAÇÃO - UM SEMINÁRIO DE INVESTIGAÇÃO INTERNACIONAL, 1., 2014, Porto. Anais... Porto: Universidade do Porto, pp. 269-285, 2014.

RODRIGUES, I. M. F. M. Centros de Arte Contemporânea em edifícios históricos: Três casos de estudo. 2012. 248 f. Dissertação (Mestrado Integrado em Arquitectura).- Universidade de Coimbra, Coimbra, 2012.

SECRETARIA MUNICIPAL DA CULTURA. Manual do Usuário. 1.ed. Pelotas: Nova Prova, 2008. 104p.

SILVA, D. D. S. Diagnóstico de patologias em fachadas utilizando termografia. Dissertação (Mestrado em Engenharia Civil) - Faculdade de Engenharia, Universidade do Porto, Porto, 2012.

SILVA, H. E.; HENRIQUES, F. M. A. Microclimatic analysis of historic buildings: a new methodology for temperate climates. Building and Environment, Portugal, v. 82, pp. 381-387, set. 2014.

SILVA, H. E.; HENRIQUES, F. M. A. Análise microclimática de um edifício histórico em clima temperado: limites sustentáveis para a correta conservação dos materiais. Ambiente Construído, Porto Alegre, v. 15, n. 2, p. 65-77, abr./jun. 2015.

STERFLINGER, K. Fungi: Their role in deterioration on cultural heritage. Fungal Biology Reviews, v. 24, pp. 4655, 2010. 